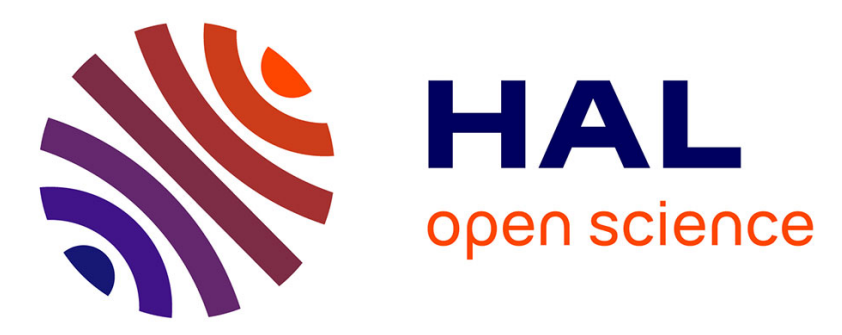

\title{
Antenna Characterization in Reverberation Chamber at Frequencies Close to the Lowest Usable Frequency
}

\author{
Wafa Krouka, Francois Sarrazin, Elodie Richalot
}

\section{To cite this version:}

Wafa Krouka, Francois Sarrazin, Elodie Richalot. Antenna Characterization in Reverberation Chamber at Frequencies Close to the Lowest Usable Frequency. 2020 IEEE International Symposium on Antennas and Propagation \& USNC/URSI National Radio Science Meeting, Jul 2020, Montréal, Canada. hal-03113199

\author{
HAL Id: hal-03113199 \\ https://hal.science/hal-03113199
}

Submitted on 18 Jan 2021

HAL is a multi-disciplinary open access archive for the deposit and dissemination of scientific research documents, whether they are published or not. The documents may come from teaching and research institutions in France or abroad, or from public or private research centers.
L'archive ouverte pluridisciplinaire HAL, est destinée au dépôt et à la diffusion de documents scientifiques de niveau recherche, publiés ou non, émanant des établissements d'enseignement et de recherche français ou étrangers, des laboratoires publics ou privés. 


\title{
Antenna Characterization in Reverberation Chamber at Frequencies Close to the Lowest Usable Frequency
}

\author{
W. Krouka, F. Sarrazin, E. Richalot \\ ESYCOM Laboratory (UMR 9007), Univ Gustave Eiffel, CNRS, \\ 77454 Marne-la-Vallée Cedex 2, France \\ Email:wafa.krouka@u-pem.fr
}

\begin{abstract}
Research works done in the last years have shown a growing interest for antenna characterization measurements within Reverberation Chambers (RCs). Several studies on antenna characterization within RCs have led to interesting results for gain, radiation pattern and efficiency. In this work, a similar study is conducted at frequencies close to the Lowest Usable Frequency (LUF) of an RC. This study aims at obtaining a better understanding of the limitations of antenna characterization methods as well as the accuracy of the obtained results when measurements are conducted close to the LUF.
\end{abstract}

\section{INTRODUCTION}

In addition to their universal characteristics, each reverberation chamber (RC) has some intrinsic properties that tightly depend on the losses inside the chamber, the dimensions of the chamber and the efficiency of the used stirring technique. The Lowest Usable Frequency (LUF) is one of these main properties, representing the frequency above which we consider that the RC presents an ideal behaviour (homogeneous and isotropic field within the working volume). Thus, in order to have accurate antenna characterization, measurements need to be conducted at frequencies far enough from the LUF as presented in [1] where measurements frequency range is above $1 \mathrm{GHz}$ for an RC LUF around $400 \mathrm{MHz}$. In [2], measurements are also conducted at frequencies higher than the LUF estimated at $200 \mathrm{MHz}$. In this paper, we present radiation efficiency results of a patch antenna obtained from measurements conducted in two different RCs using a nonreference antenna measurement technique [1], [3]. The patch is a miniature antenna inspired from [4] combining different miniaturization techniques. It consists on a circularly-shaped monopole with an IFA-like short circuit and terminated by a capacitive load. It is printed on an Arlon $25 \mathrm{~N}$ substrate, and designed to resonate at $400 \mathrm{MHz}$. The second antenna used to measure a transmission coefficient is a classical logperiodic antenna working in the frequency range $[340 \mathrm{MHz}-$ $4 \mathrm{GHz}$. Picture of both antennas are presented in Fig. 1. In Fig. 2, we present both RCs used for measurements. The IETR $\mathrm{RC}$ is characterized by a volume of $93.35 \mathrm{~m}^{3}$, a LUF around $200 \mathrm{MHz}$ and a large metallic mechanical stirrer. As a welloperation of this environment is expected with 56 uncorrelated stirrer positions at $400 \mathrm{MHz}$, only one configuration of the measurement setup (antenna location) is considered in this
RC. On the other hand, the ESYCOM RC is characterized with a volume of $19.11 \mathrm{~m}^{3}$, a LUF around $400 \mathrm{MHz}$ and is equipped with a vertical metallic stirrer. To overcome the lack of measurement accuracy close to the RC LUF (only 16 uncorrelated stirrer positions around $400 \mathrm{MHz}$ ), both antennas are displaced within the $\mathrm{RC}$ working volume (where the fields are expected to be uniform) so that measurements are collected at 5 different locations of the antennas. This process allows having a comparable number of uncorrelated states in both RCs.

\section{MeAsurements}

Measurements are conducted over the same frequency range [300 MHz - $500 \mathrm{MHz}$ ] and 1001 equally spaced frequency samples in both RCs. The frequency range is carefully chosen to be around the LUF of the ESYCOM RC and far enough from the LUF of the IETR RC in order to compare the impact of RC characteristics on antenna radiation efficiency
Patch antenna

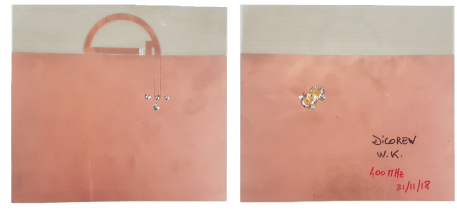

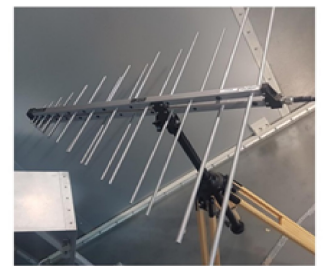

Log-periodic antenna
Fig. 1. Measurement antennas.

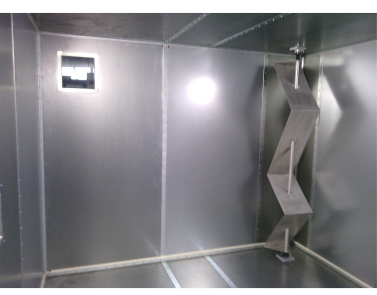

ESYCOM RC

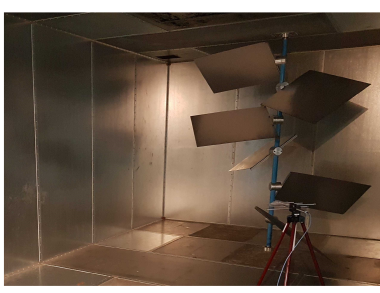

IETR RC
Fig. 2. Measurement environments. 


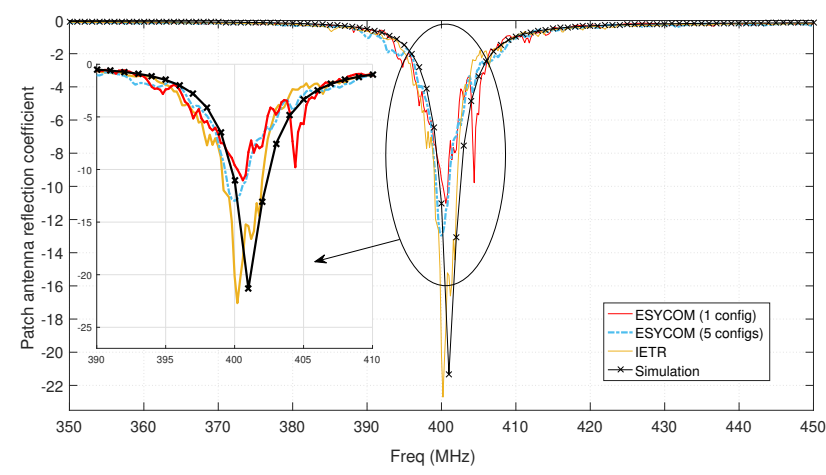

Fig. 3. Patch antenna reflection coefficient.

measurements. As detailed in [1], [3], the patch antenna radiation efficiency $\eta_{\text {rad }}$ is calculated using the equation below

$$
\eta_{\mathrm{rad}}=\sqrt{\frac{\left\langle\left|S_{11, \mathrm{~s}}\right|^{2}\right\rangle}{\left(1-\left|\left\langle S_{11}\right\rangle\right|^{2}\right)^{2}} \frac{C_{\mathrm{RC}}}{\omega \cdot \tau_{\mathrm{RC}} \cdot e_{\mathrm{b}}}}
$$

with

$$
e_{\mathrm{b}}=\frac{\sqrt{\left\langle\left|S_{11, \mathrm{~s}}\right|^{2}\right\rangle\left\langle\left|S_{22, \mathrm{~s}}\right|^{2}\right\rangle}}{\left\langle\left|S_{21, \mathrm{~s}}\right|^{2}\right\rangle}
$$

and $C_{\mathrm{RC}}=16 \pi^{2} V / \lambda^{3}, S_{i j, \mathrm{~s}}=S_{i j}-\left\langle S_{i j}\right\rangle$ is the stirred component of $S_{i j}, S_{11}$ is the patch antenna reflection coefficient, $\langle$.$\rangle is the average over measurement configurations and/or$ stirrer positions, $e_{\mathrm{b}}$ is the enhanced backscattering coefficient, $V$ is the chamber volume and $\lambda$ is the wavelength.

\section{EXPERIMENTAL RESULTS}

Fig. 3 presents the reflection coefficient of the patch antenna measured in both RCs. The obtained results are compared to simulated ones. When only one antenna configuration is considered in ESYCOM RC, we notice important fluctuations compared to IETR RC measurements which are closer to simulation results. When the average is calculated over the 5 setup configurations in ESYCOM RC (source stirring), the resulting curve presents less fluctuations and is in better agreement to IETR RC (TABLE I). It shows that, when measurements are conducted higher than the LUF (IETR RC), mechanical stirring is enough to accurately estimate the reflection coefficient. On the other hand, a source stirring is necessary in addition to the mechanical stirring for measurements close to the LUF (ESYCOM RC) to increase the accuracy.

TABLE I

RELATIVE DIFFERENCES BETWEEN MEASUREMENT RESULTS IN ESYCOM AND IETR RCS.

\begin{tabular}{|c|c|c|}
\hline Reverberation chamber & Reflection coefficient & Radiation efficiency \\
\hline ESYCOM RC $(1$ config) & $6.04 \%$ in linear & $30.88 \%$ \\
\hline ESYCOM RC $(5$ configs) & $4.56 \%$ in linear & $12.72 \%$ \\
\hline
\end{tabular}

We evaluate the patch antenna radiation efficiency using (1) in both RCs. Results are presented in Fig. 4 and are compared

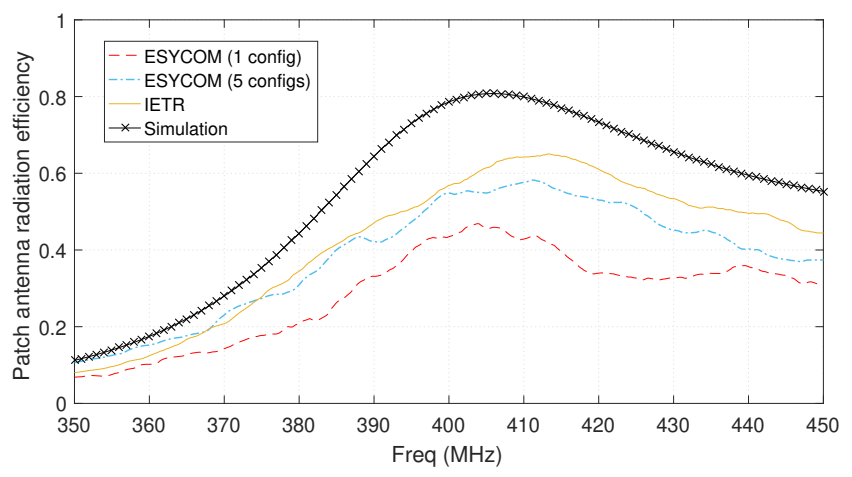

Fig. 4. Patch antenna radiation efficiency.

to simulation ones. The simulated efficiency reaches $80 \%$ at $400 \mathrm{MHz}$ while it remains below $60 \%$ for the IETR result. Simulated radiation efficiency of miniature antenna is usually overestimated which may explain this difference. However, we highlight that the result obtained at ESYCOM with only one antenna configuration leads to only $45 \%$ efficiency. Combining source stirring and mechanical stirring in ESYCOM RC measurements allows obtaining an efficiency very similar to the one obtained in IETR RC. Relative differences between the efficiencies obtained on both RCs are presented in TABLE I.

\section{CONCLUSION}

In order to underline the impact of the RC characteristics on measurement accuracy, we compare in this paper radiation efficiency measurements of a patch antenna obtained in two different RCs. Measurement frequency range is chosen to be close to the LUF of one RC and far enough from the second one. When measurements are conducted close to the LUF, important fluctuations of the reflection coefficient and an underestimation of the radiation efficiency are obtained. To overcome this lack of accuracy, a source stirring is proposed; with 5 different measurement configurations combined to the mechanical stirring, the obtained results become similar to the ones obtained in the larger RC.

\section{ACKNOWLEDGEMENT}

The authors wish to thank Philippe Besnier and Jérôme Sol from IETR laboratory in Rennes, France, for their technical support and fruitful discussions.

\section{REFERENCES}

[1] W. Krouka, F. Sarrazin, E. Richalot, "Influence of the reverberation chamber on antenna characterization performances", Int. Symp. on Electromagn. Compat., Amsterdam, vol. 60, pp. 329-333, August 2018.

[2] P. Besnier, J. Sol, A. Presse, C. Lemoine, A. C. Tarot, "Antenna efficiency measurement from quality factor estimation in reverberation chamber", European Microwave Conference, London, pp. 715-718, Oct. 2016.

[3] C. L. Holloway, H. A. Shah, R. J. Pirkl, W. F. Young, D. A. Hill, J. Ladbury, "Reverberation Chamber Techniques for Determining the Radiation and Total Efficiency of Antennas", IEEE Trans. antennas propagat., vol. 60, no. 4, Apr. 2012.

[4] F. Sarrazin, S. Pflaum, C. Delaveaud, "Radiation Efficiency Improvement of a Balanced Miniature IFA-Inspired Circular Antenna," IEEE Antennas Wireless Propag. Lett., vol. 16, pp. 1309-1312, 2017. 